\title{
Origen del concepto de monoparentalidad. Un ejercicio de contextualización sociohistórica
}

\author{
Manuela Avilés Hernández \\ Universidad de Murcia \\ manoliaviles@um.es
}

Aceptado: 22-06-2012

\section{Resumen}

Aunque las situaciones monoparentales han estado presentes a lo largo de toda la historia, el concepto que se utiliza en la actualidad para referirse a ellas es relativamente joven, pues no fue hasta bien entrada la segunda mitad del siglo XX cuando se dieron las condiciones sociales y estructurales necesarias para su aparición. Pero, ¿̨cuáles fueron esas condiciones especiales que posibilitaron el nacimiento del término monoparentalidad?, ¿qué otros conceptos se empleaban hasta aquel momento?, ¿esta expresión seguirá existiendo durante las próximas décadas o, por el contrario, irá sufriendo cambios?, ¿¿de ser así, en qué dirección irán esos cambios? Atendiendo a estas cuestiones, en este artículo, se realiza un análisis sobre la evolución que ha ido experimentando, a lo largo del siglo XX, la terminología empleada para referirse a las hoy conocidas como familias monoparentales, prestando especial atención al contexto sociohistórico en el que se originó este término y al futuro hasta ahora incierto que le aguarda.

Palabras clave: familia rota; familia incompleta; familia monoparental; familia monomarental; evolución conceptual.

\section{Abstract. Origin of the Concept 'Single Parenthood': An Exercise of Sociohistorical Contextualization}

Although single-parent families have existed throughout history, the concept that we currently use to refer to them is relatively recent as the social and structural conditions necessary for its existence did not arise until the second half of the 20th century. But what were these special conditions that made the coining of the term 'single parenthood' possible? What concepts were used up to that moment? Will this expression exist over the next decades or, on the contrary, will it undergo changes and in what direction will these changes go? To answer these questions, in this paper we analyze the evolution of the terminology used to designate single-parent families during the 20th century, paying special attention to the sociohistorical context in which the term originated and its yet unknown future.

Keywords: broken families; incomplete families; single-parent families; single-mother families; conceptual evolution. 


\section{Sumario}

\section{Introducción}

2. La familia nuclear biparental como modelo dominante en la sociedad moderna. Implicaciones y consecuencias sobre la monoparentalidad

3. Las situaciones monoparentales a partir de la segunda mitad del siglo xx. Cambios en el discurso problematizador existente en relación con ellas y origen del concepto anglosajón
4. La monoparentalidad en la España cambiante de finales del siglo xx. Origen del concepto español

5. Reflexiones finales

Referencias bibliográficas

\section{Introducción}

Las situaciones conocidas en la actualidad como monoparentales han sido una constante a lo largo de la historia. Prueba de ello es que, como destacan algunos investigadores (Fernández y Tobío, 1998: 52; Iglesias de Ussel, 1998: 238 y 239; Reher, 1996: 148-160), siempre han existido las procreaciones fuera del matrimonio, las situaciones de viudedad y las separaciones conyugales, generadas no sólo por rupturas matrimoniales, sino también por una amplia diversidad de causas sociales, como el ingreso en prisión, la participación en la guerra o la emigración hacia otras ciudades o países por parte de uno de los miembros de la pareja.

A pesar de su presencia continua en la sociedad, estas formas familiares no siempre han mostrado las mismas características sociales y estructurales, sino que, por el contrario, y al igual que la institución familiar en general, han estado fuertemente vinculadas al contexto social en el que se enmarcaban. En consecuencia, han ido experimentando serios cambios en el devenir de la historia, en relación con aspectos tan diversos como sus propias características intrínsecas, su incidencia real sobre el conjunto de la sociedad y la percepción que se tenía de ellas.

Un ejemplo del cambio constante al que han estado sometidas y de la estrecha vinculación que presentan con respecto al contexto social en el que se inscriben puede encontrarse en un aspecto tan básico como lo es el hecho de que no siempre se haya utilizado el mismo concepto para designarlas. Es más, el término que se emplea actualmente apenas cuenta con unas pocas décadas de vida, pues no fue hasta bien entrada la segunda mitad del siglo XX cuando se dieron las condiciones sociales y estructurales necesarias para su aparición. Pero, ¿̨cuáles fueron esas condiciones especiales que posibilitaron el nacimiento del término monoparentalidad?, ¿qué otros conceptos se empleaban hasta aquel momento?, ¿esta expresión seguirá existiendo durante las próximas décadas o, por el contrario, irá sufriendo cambios?, ¿̇e ser así, en qué dirección irán esos cambios?

Teniendo en cuenta que el número de hogares españoles que presentan la condición de monoparental continúa aumentando, con las consecuencias e implica- 
ciones que ello conlleva para la sociedad, y que, además, el interés que suscita este objeto de estudio, así como la producción científica que se ha generado durante los últimos años en relación con él, ha sido, y sigue siendo, francamente elevada, merece la pena centrarnos por un momento en estos interrogantes, buscando conocer con mayor detalle de dónde viene y hacia dónde se dirige la terminología que se emplea para designar a todas aquellas estructuras familiares en las que un único progenitor asume en solitario el cuidado de sus hijos dependientes.

En base a estas premisas, en este artículo, se realiza un análisis sobre la evolución que ha ido experimentando, a lo largo del siglo XX, el marco conceptual utilizado para referirse a las hoy conocidas como familias monoparentales, prestando especial atención al contexto sociohistórico en el que se originó este término. Para comenzar, se plantean las principales implicaciones y consecuencias que tuvo sobre ellas y sobre la forma de denominarlas la generalización de la familia nuclear biparental como modelo dominante en la sociedad moderna. A continuación, se analizan las diversas transformaciones sociales y, sobre todo, familiares que se sucedieron a partir de los años sesenta y setenta en determinados países como Estados Unidos e Inglaterra, así como la manera en la que afectaron a las propias familias monoparentales, al discurso existente en relación con ellas y a la terminología empleada hasta aquel momento para referirlas. Posteriormente, se examina la situación específica que vivieron estas formas familiares en la España cambiante de finales del siglo XX y cómo se originó en nuestro país el concepto que se utiliza en la actualidad para nombrarlas. Todo este análisis se completa con unas consideraciones finales en las que, a modo de debate, se reflexiona sobre el futuro hasta ahora incierto que aguarda al concepto de monoparentalidad.

\section{La familia nuclear biparental como modelo dominante en la sociedad moderna. Implicaciones y consecuencias sobre la monoparentalidad}

Con el proceso de industrialización y el conjunto de cambios acaecidos en la sociedad, la familia nuclear biparental o, como algunos investigadores la han denominado, familia nuclear parsoniana, compuesta por padre, madre e hijos, se fue haciendo cada vez más presente en la realidad social y familiar del siglo XX, hasta el punto de convertirse en la forma familiar dominante en la sociedad moderna ${ }^{1}$.

1. En ese proceso de expansión y consolidación posterior como modelo dominante, el funcionalismo estructural, que es una de las corrientes teóricas más importantes y destacadas dentro del campo de la sociología, y dentro, especialmente, de la sociología de la familia, desempeñó un papel clave, pues su influencia sobre el discurso familiar de la época era más que notoria. Dentro del funcionalismo estructural destacan, por su importancia y por la repercusión social que tuvieron, las aportaciones del investigador Talcott Parsons, cuyos planteamientos teóricos son los que terminaron guiando, y asimismo dominando, parte del discurso familiar de mediados del siglo XX. Si se desea ahondar en la teoría que este investigador elaboró sobre la familia, pueden consultarse, entre otras, las siguientes obras: Talcott PARSONS (1955), Éléments pour une sociologie de l'action, París, Libraire Plon, y Talcott PARSONS y Robert F. BALES (1955), Family, Socialization and Interaction Process, Nueva York, The Free Press of Glencoe. 
Este hecho tuvo serias y duras consecuencias para todas aquellas formas de organización familiar que, por diversos motivos, presentaban una estructura diferente a la del modelo dominante. En concreto, aquellos grupos familiares que no se conformaban con la familia nuclear biparental empezaron a ser considerados disfuncionales y, por lo tanto, negativos para el conjunto de la sociedad, ya que, en teoría, no presentaban la estructura necesaria para el desempeño correcto de sus funciones. La mayoría se convirtieron en objeto de rechazo y exclusión social, incluso algunos llegaron a ser concebidos como marginales, pues se creía que generaban delincuencia, consumo de drogas, prostitución, niños conflictivos, pobreza, etc.

Éste fue el caso de algunas de las modalidades de familia que hoy quedan englobadas bajo el concepto monoparentalidad. Todas ellas eran formas familiares que rompían con esa estructura nuclear biparental que se consideraba ideal, puesto que, a pesar de ser nucleares, carecían de un progenitor, en la mayoría de los casos el padre, por lo que, según los planteamientos teóricos dominantes, no estaban funcionalmente adaptadas a la sociedad moderna. Pese a las duras críticas que suscitaban, no todas las situaciones monoparentales eran percibidas o tratadas de igual forma, sino que, por el contrario, existía una clara diferenciación social y moral entre ellas, en función de la causa que había generado su condición de monoparental. Así, se observa que aquellas que se percibían como exentas de culpa, es decir, las que surgían como consecuencia de sucesos involuntarios, como la viudedad o las separaciones conyugales transitorias $^{2}$, gozaban de un cierto apoyo y reconocimiento social. Por el contrario, las consideradas voluntarias, generadas en su mayoría por una ruptura conyugal o un nacimiento fuera del matrimonio, eran objeto de un fuerte rechazo social.

En torno a estas diferencias entre unas y otras formas de monoparentalidad, la investigadora Miri Song (1996: 379) explica que, en la sociedad de la época, llegó a existir una clara jerarquía entre ellas, en términos fundamentalmente moralistas, en base a la causa que había provocado su condición. Dentro de esta jerarquía, las familias monoparentales encabezadas por una mujer viuda ocupaban la posición más elevada, de ahí que fuesen el grupo monoparental mejor tratado y más apoyado por los distintos sectores sociales. Así lo evidencia el hecho de que, en países como Inglaterra, pronto se decidiera conceder a las mujeres viudas con hijos a su cargo una pensión económica, con lo que se convirtieron en el único grupo monoparental que recibía apoyo estatal. El segundo puesto de esta jerarquía lo ocupaban las familias monoparentales encabezadas por una mujer separada o divorciada, quienes, a pesar de su baja incidencia sobre el conjunto de la sociedad, provocaban un escándalo social y moral, pues, en aquel momento histórico, aún no se contemplaba como algo lícito, y por tanto viable, la disolución de un vínculo matrimonial. El último

2. Entiéndase por separación conyugal transitoria aquella que se generaba como consecuencia de diversos hechos sociales, entre los que destaca, por la elevada frecuencia con la que se daba, la emigración por razones laborales o económicas de uno de los miembros de la pareja, generalmente del hombre. 
$y$, por consiguiente, el grupo monoparental peor percibido, era el constituido por las madres solteras, quienes sufrían un importante estigma social. La alarma moral que despertaban estas mujeres era tan acentuada que, generalmente, se asociaban con el consumo de drogas, el libertinaje, la falta de control y, en ocasiones, incluso, con la prostitución. Además, según afirma Miri Song (1996: 381), en este contexto histórico fue bastante común su patologización por parte de trabajadores sociales y otros profesionales, quienes las consideraban de naturaleza inmadura y poco inteligentes. Prueba de ello es que, en la literatura psicosocial de principios de los años cincuenta, era común representarlas o referirse a ellas como mujeres patológicamente desequilibradas (Finch y Summerfield, 1999: 14). Los hijos de las madres solteras sufrían también una fuerte estigmatización, hasta el punto de ser considerados como hijos de segunda clase por parte de determinados sectores sociales. De hecho, ciertos trabajadores sociales y algunos investigadores de la época estaban convencidos de que los hijos nacidos de una madre soltera presentaban tasas de mortalidad infantil más elevadas que los nacidos de familias nucleares biparentales, así como unos niveles de éxito personal y profesional inferiores (Song, 1996: 381). Se observa, pues, que la consideración social era muy diferente, casi opuesta, entre las situaciones monoparentales voluntarias e involuntarias. Los factores morales elevaban, según apuntan los expertos Juan Antonio Fernández y Constanza Tobío (1998: 52), una barrera entre ambas situaciones que, de alguna manera, ocultaba el rasgo que todas ellas tenían en común: «la carga de los hijos en soledad».

Desde esta diferenciación negativa entre situaciones monoparentales voluntarias e involuntarias, se fue gestando, explica la socióloga Sara Barrón (1998: 216), toda una tradición de investigación, orientada a detectar los defectos que producía, no tanto la ausencia de biparentalidad, sino, más bien, la falta de un modelo masculino que diera estabilidad y autoridad al conjunto familiar. Es decir, fue, sobre todo, la condición femenina de la jefatura familiar lo que se conceptualizó en términos patológicos y, a su vez, suscitó la necesidad de ahondar en el estudio de las consecuencias negativas que la ausencia del progenitor varón podía llegar a tener sobre la estructura familiar y, más concretamente, sobre los hijos. Fue así como, a partir de los años cincuenta, empezaron a desarrollarse numerosas investigaciones dentro del campo de las ciencias sociales en las que se utilizaba, como principal estrategia de análisis, la comparación de diversos niños, en su mayoría varones, procedentes de familias donde el padre se encontraba presente y donde éste estaba ausente. Aunque la literatura que se generó a este respecto fue extensa y, en algunos casos, contradictora, parte de las investigaciones vinieron a confirmar que los niños que crecían sin sus padres presentaban problemas y dificultades en áreas de su desarrollo como la identidad de género, los roles sexuales, la conducta, el bienestar a nivel psicosocial y el éxito en el ámbito académico.

Entre estas investigaciones, destacan algunas como la realizada por el estadounidense Ivan Russell (1957), quien se centró en el análisis de uno de los aspectos que más preocupaba a la sociedad desde, prácticamente, inicios del 
siglo XX. Se trataba de la posible relación entre delincuencia y monoparentalidad. Para ello, estudió a un total de 348 niños y jóvenes menores de 18 años, pertenecientes a hogares en los que faltaba uno de los progenitores y en los que ambos estaban presentes (174 de cada hogar). Su objetivo se centraba en determinar si aquéllos que pertenecían a hogares desestructurados presentaban más problemas a nivel conductual que los que crecían en familias intactas. Los resultados obtenidos permitieron concluir a Russell que, en efecto, esto era así. En concreto, los hijos de familias desestructuradas mentían y robaban en una proporción significativamente superior a la del resto. Asimismo, el estudio reveló que los niños y jóvenes que vivían sin uno de sus progenitores a causa de un divorcio presentaban mayores niveles de desobediencia, ira extrema y enuresis que aquellos que vivían con un único progenitor como consecuencia del fallecimiento del otro. Éstos últimos, sin embargo, presentaban mayores dificultades en el ámbito escolar.

El psicólogo Henry Biller $(1968,1969)$, por su parte, se centró en el estudio de otro de los aspectos que, en conexión con la ausencia del progenitor varón, inquietaba también a la sociedad de la época. Este segundo problema consistía en los supuestos efectos negativos que podía llegar a tener sobre los hijos varones la ausencia de un modelo de conducta masculina que les sirviera de referente y apoyo en la elaboración de su propio autoconcepto y en el aprendizaje de los roles asociados a su género. Esta preocupación, bastante extendida entre los psicólogos, reposaba en el papel tan determinante que los planteamientos teóricos de la época habían terminado concediendo al padre como modelo de conducta masculina ${ }^{3}$. A través de sus investigaciones, Biller confirmó que los niños varones que crecían sin sus padres, sobre todo aquellos que se encontraban en edad preescolar, tenían menos posibilidades de interactuar con una figura masculina, lo que les ocasionaba serias dificultades en el desarrollo de su propia masculinidad y en el aprendizaje de los roles asociados a su género. Estas dificultades se acentuaban conforme la edad del niño decrecía, ya que las posibilidades de interactuar con otras figuras masculinas diferentes a las que componían la unidad familiar se reducían. Asimismo, los problemas se acentuaban también en aquellos casos en los que el marco de referencia familiar estaba afectado por la ausencia de otros varones como abuelos, tíos o hermanos.

En este contexto, en el que el concepto de familia monoparental no había nacido todavía, era usual referirse a este tipo de familias con expresiones como unmarried women, unsupported mother, deserted wives, dissociated families, fatherless families, broken homes, incomplete families, father-absent families, familles privées de père o familles dissociées. Una prueba de las dimensiones que llegaban a alcanzar las diferencias morales y sociales existentes, en cuanto a la

3. Tradicionalmente los hombres se habían encargado de asumir un rol centrado en el mantenimiento económico de la unidad familiar. Sin embargo, a partir de la Segunda Guerra Mundial, la conceptualización en torno a los roles y las responsabilidades paternas se modificó (Lamb, 1986), de tal forma que, además de seguir procurando el bienestar económico de la familia, los hombres pasaron a ejercer un papel clave en el proceso de socialización de sus hijos como modelo de conducta masculina que éstos últimos debían imitar. 
percepción y el tratamiento de las distintas formas de monoparentalidad, es que estos conceptos no se utilizaban de forma indistinta, sino que, por el contrario, cada uno de ellos se reservaba para designar a un tipo concreto de familia monoparental. Así, el concepto inglés father-absent families se utilizaba, tan sólo, en aquellos casos en los que el padre estaba ausente a causa de su muerte (Deven, 1986: 16). Lo mismo sucedía con el término francés familles privées de père, reservado exclusivamente, y según explica la socióloga feminista Nadine Lefaucheur (1986: 74), para aquellas situaciones en las que la monoparentalidad se generaba como consecuencia del fallecimiento del padre o de su emigración por razones económicas y laborales. El resto de conceptos resultaban bastante más ofensivos y peyorativos que los dos anteriores y se utilizaban en aquellos casos en los que la monoparentalidad se generaba como consecuencia de un divorcio, es el ejemplo de broken homes, o de un nacimiento fuera del matrimonio, como unmarried women. De hecho, estos últimos conceptos se introdujeron, precisamente, porque, en el discurso social y moral de la época, era inconcebible que madres viudas, solteras y divorciadas pudieran quedar englobadas bajo una misma categoría conceptual. Fueron los psicólogos y los psiquiatras ingleses y estadounidenses quienes los acuñaron por primera vez, para responder así a la necesidad que había en la sociedad de distinguir entre los distintos tipos de monoparentalidad y explicar, además, que gran parte de los problemas sociales, especialmente en términos de delincuencia, estaban asociados con la falta del progenitor varón en el hogar, a causa, sobre todo, de un divorcio.

Zonas como España y Latinoamérica presentaban también una amplia pluralidad de etiquetas, traducidas en su mayoría del inglés, como familia incompleta, familia disociada, hogar roto, familia desestructurada, familia defectuosa, etc., que, al igual que las imperantes en el contexto internacional, buscaban enfatizar esa ausencia del progenitor varón que las caracterizaba y que, a su vez, era lo que las conceptualizaba en términos negativos. Varias de estas expresiones han sido fuertemente criticadas por algunos científicos sociales expertos en la materia, por considerar unos que eran peyorativas y otros que no representaban bien la realidad a la que estaban referidas. Algunos ejemplos de estas críticas se pueden encontrar en las aportaciones de investigadores como M. ${ }^{a}$ Ángeles Durán (1988: 14), quien plantea que el término familia incompleta conllevaba una carga ideológica demasiado fuerte, ya que, en cierta medida, remitía a la idea de que lo completo era lo perfecto y que, por consiguiente, lo completo y perfecto era la familia nuclear compuesta por padre, madre e hijos. A esta crítica, se suman otras como la de Julio Iglesias de Ussel (1998: 238), quien considera que esta misma expresión implicaba la falta de desempeño de su papel por parte de algunos de los progenitores, lo que no necesariamente ocurría en todos los casos de divorcio o separación. Este mismo investigador cuestiona también el uso de la categoría familia rota, puesto que, según él, no incluía a las madres solteras, con lo que no englobaba a la pluralidad de realidades posibles. Por otra parte, Nadine Lefaucheur (1988: 156) destaca que las etiquetas familia incompleta y familia disociada, así como sus homólogas 
francesas famille incomplète y famille dissociée, no sólo se utilizaban para referirse a aquellos casos en los que faltaba al menos uno de los dos progenitores, sino que, además, servían para denominar a las familias que hoy consideramos recompuestas o reconstituidas. Al mismo tiempo, se utilizaban para designar a aquellas formas familiares en las que las normas sobre roles sexuales no se respetaban, bien por inversión de papeles ${ }^{4} \mathrm{o}$, sobre todo, porque el reparto natural de dichos papeles según el sexo del progenitor resultaba imposible o se veía perturbado por la ausencia de uno de ellos.

\section{Las situaciones monoparentales a partir de la segunda mitad del siglo XX. Cambios en el discurso problematizador existente en relación con ellas y origen del concepto anglosajón}

Las diferencias que, en términos moralistas, existían entre los distintos tipos de monoparentalidad comenzaron a disiparse a finales de los años sesenta y principios de los setenta en determinados países como Estados Unidos e Inglaterra. Este hecho aconteció como consecuencia del profundo cambio social, ideológico y demográfico que se empezó a producir en estas zonas geográficas y que provocó un incremento considerable en el número de situaciones monoparentales, así como la aparición de numerosas críticas hacia la política social existente (Treviño, 2006: 37). Estas críticas procedían, en su mayoría, de ciertos grupos de presión y de algunos investigadores sociales, y se centraban, como explican las sociólogas feministas Jane Lewis y Kathleen Kiernan (1996: 379), en denunciar las necesidades materiales comunes que presentaban todas las familias monoparentales y las históricas, e injustas, divisiones entre madres viudas, divorciadas y solteras.

En concreto, en estas sociedades, se inició lo que determinados investigadores (Cliquet, 1991; Lesthaeghe, 1995; Rees, 1996; Van de Kaa, 1987) han denominado segunda transición demográfica, caracterizada por una disminución en las tasas de fecundidad y nupcialidad, un retraso en el calendario nupcial, un incremento en el fenómeno de la cohabitación y un aumento en el número de separaciones, divorcios y nacimientos fuera del matrimonio. Todo ello originó la aparición de una importante cantidad de familias monoparentales, sobre todo femeninas, puesto que, ante un nacimiento extramatrimonial, la mayoría de los niños permanecían con la madre, de la misma manera que, ante una ruptura conyugal, eran las madres las que, por regla general, asumían la custodia y el cuidado de sus hijos dependientes.

Esta realidad queda corroborada a través de los datos estadísticos existentes en ese momento y, según los cuales, las familias estadounidenses encabezadas por una mujer pasaron de representar, en 1960, el 7\% del total de familias a

4. Según Nadine Lefaucheur, algunos autores han considerado «disociadas» las familias en las que la madre se mostraba autoritaria y el padre dulce y sumiso; otros han calificado de "cotidianamente disociadas» aquellas familias en las que la mujer abandonaba su hogar durante el día para ir a trabajar. 
suponer cerca del 19\% en 1973. Esto quiere decir que, en apenas trece años, estas formas familiares triplicaron su presencia en la sociedad estadounidense, puesto que aumentaron de 1,89 millones a 5,72, tal y como apuntan los investigadores Lowell Lima y Robert Harris (1988: 21). Este incremento, como ya se ha señalado, se produjo, fundamentalmente, como consecuencia del aumento en el número de divorcios y nacimientos extramatrimoniales. Según estos mismos investigadores (1988: 20 y 21), la proporción de divorcios en Estados Unidos por cada mil mujeres casadas de 15 o más años aumentó de 10,3, en 1950, a 22,8, en 1980. El número de divorcios pasó de 392.000, en 1960, a 708.000, en 1970, y a 1,2 millones, en 1980, de forma que los correspondientes a 1980 triplicaron la cantidad registrada en el año 1960. El número de niños estadounidenses que se vieron envueltos en un divorcio aumentó de 463.000, en 1960; a 870.000, en 1970, y a 1,2 millones, en 1980, con lo que, en este último año, el dato era 2,5 veces superior al de 1960. Igualmente, y según continúan apuntando Lima y Harris, el número de nacimientos extramatrimoniales experimentó también un profundo incremento, pues pasaron de suponer el 4\% del total de nacimientos, en 1950; al 5,3\%, en 1960; al 10,7\%, en 1970, y al 17,1\%, en 1979, lo que supuso, en apenas tres décadas, una cuadruplicación en el número de nacimientos extramatrimoniales registrados en Estados Unidos. Estos investigadores añaden que la tasa de nacimientos por cada mil mujeres no casadas de entre 15 y 44 años se dobló, ya que pasó de 14,1, en 1950 , a 27,8 , en 1979.

Tendencias similares se registraron en determinados países europeos, hasta el punto de que las Naciones Unidas estimaron que, entre 1960 y 1980, la tasa de divorcios se había triplicado en la zona norte de Europa, con lo que, entre el 25 y el 50 por ciento de los matrimonios que se celebraban terminaban disolviéndose (O'Connell, 1994: 18). En el caso concreto de Gran Bretaña, la proporción de divorcios por cada mil habitantes casados pasó de 2, en 1960; a 9,6, en 1975, y a 12, en 1980. Junto al incremento en el número de rupturas matrimoniales, la tasa de nacimientos fuera del matrimonio también experimentó un importante crecimiento en este país, de tal forma que, en un período de 15 años, los comprendidos entre 1955 y 1970, el dato se dobló, y llegó a alcanzar, en esta última fecha, la cifra de 21,5 nacimientos extramatrimoniales por cada mil mujeres solteras, divorciadas y viudas de edades comprendidas entre los 15 y los 44 años (Lewis y Kiernan, 1996: 375).

Todos estos cambios evidencian que, en realidad, lo que estaba teniendo lugar en la sociedad de la época era una profunda e intensa modificación en términos fundamentalmente ideológicos y culturales que tuvo su correspondiente manifestación a nivel demográfico. Así lo han constatado numerosos investigadores sociales como Ronald Inglehart (1998: 40-42), quien defiende que, durante los años posteriores a la Segunda Guerra Mundial, se registraron una serie de cambios importantes en las sociedades industriales avanzadas, como un profundo crecimiento económico sin precedentes históricos y el surgimiento del estado moderno del bienestar, que hicieron que las cohortes de la posguerra crecieran bajo unas condiciones completamente diferentes a las 
que habían rodeado a las generaciones anteriores. En concreto, estas cohortes se desarrollaron con un sentimiento de seguridad física y económica, inexistente hasta aquel momento, que contribuyó a disminuir la sensación general de vulnerabilidad y derivó en un proceso de cambio de valores a nivel intergeneracional. Fue de esta manera como, según Inglehart, se fue pasando de una sociedad industrial avanzada, dominada por unos valores materialistas centrados en la consecución de seguridad económica y física, a una sociedad posmoderna, caracterizada por unos valores posmaterialistas que priorizan aspectos como la autoexpresión y la calidad de vida. La preeminencia de estos últimos valores, que, entre otras cosas, priman la autorrealización a través de la carrera profesional muy por encima de la crianza de los hijos, tuvo su correspondiente manifestación a nivel social, y transformó de forma gradual la política y las normas culturales existentes. Todos estos cambios son los que, según Inglehart, explican el descenso que, a partir de mediados de los años sesenta, registraron las tasas de natalidad y nupcialidad de las sociedades industriales avanzadas, así como el aumento notable e imparable en el número de rupturas conyugales y nacimientos extramatrimoniales.

El crecimiento que estaban experimentando las familias monoparentales femeninas, su generalizada dependencia de ayudas estatales y el riesgo de pobreza y exclusión al que estaban sometidas, ya que cada vez presentaban una situación social y económica más delicada, hicieron que la monoparentalidad dejara de concebirse como un fenómeno excepcional que provocaba rechazo y escándalo, sobre todo a nivel moral, para pasar a ser contemplado, según indica Miri Song (1996: 385), como un suceso imprevisto que le podía ocurrir a cualquiera ("[...] an event which was unplanned and unforeseen - it could happen to anyone»).

Este conjunto de cambios originó la necesidad de recategorizar a la realidad familiar compuesta por un único progenitor a cargo de su descendencia con una terminología menos peyorativa y más neutral que la existente. Fue así como, a finales de los años sesenta, y ya con mayor claridad en la década de los setenta, empezaron a surgir determinados conceptos en la literatura anglosajona para designar a estas estructuras familiares. En concreto, fueron apareciendo los términos one-parent families, single-parent families y lone-parent families ${ }^{5}$, que pretendían ser expresiones globales que, en primer lugar, abarcaran una mayor diversidad de formas monoparentales, en segundo lugar, evitaran el estigma de las denominaciones anteriores y, en tercer lugar, enfatizaran los aspectos que todas estas formas familiares tenían en común: el cuidado de los hijos en solitario.

En esta reconceptualización desempeñaron un papel clave ciertos informes oficiales como los realizados en Inglaterra a principios de los años setenta. Miri Song (1996: 385) explica que, en 1973, el prefacio del Annual Report introdujo serios cambios en el lenguaje que había utilizado hasta entonces. Por ejemplo,

5. Este último concepto es el que se ha impuesto finalmente en los países anglosajones, aunque varias investigaciones utilizan todavía el término single-parent families. 
el concepto illegitimate fue sustituido por natural y unmarried mother por single mother. Igualmente, Song añade que, en 1974, el Finer Report, que fue un informe realizado, precisamente, para determinar las condiciones de vida que presentaban las familias monoparentales ante la preocupación social que existía en torno a su aumento, abogó por el uso de términos como one-parent families, en lugar de otros más comunes hasta aquel momento, como unmarried mothers, broken families o deserted wives. La literatura especializada (Deven, 1986: 16) reconoce, a este último informe, el mérito de haber sido uno de los primeros impulsores del uso de la nueva terminología, así como uno de los que más insistentemente denunció lo insensato e injusto que resultaba el tratamiento diferenciado de las distintas formas de monoparentalidad.

Como señala Sara Barrón (1998: 218), la reconceptualización definitiva que se produjo en relación con estas formas familiares resultó sumamente operativa a nivel institucional, ya que permitió cuantificar las necesidades y los problemas comunes de un colectivo social que ya comenzaba a formar parte de la agenda de políticos y trabajadores sociales. Es más, en determinados países como Inglaterra, pronto empezaron a ser comunes las muestras de interés por parte de las administraciones públicas hacia estas formas familiares. Estas muestras se materializaron, sobre todo, a través de programas y ayudas, orientadas, en su mayoría, a paliar las necesidades económicas y el riesgo de pobreza que presentaban gran parte de las familias monoparentales. Un ejemplo se puede encontrar en el nacimiento del Family Income Supplement (FIS), que fue una ayuda dirigida, según aclara Miri Song (1996: 383), a los trabajadores a jornada completa, mal pagados y con hijos a cargo. En 1979, y teniendo en cuenta los problemas especiales a los que debían hacer frente los progenitores monoparentales, se optó por modificar el número de horas trabajadas necesarias para acceder a ella, las cuales quedaron fijadas en veinticuatro por semana. En el caso de las familias biparentales, el requisito se mantuvo en treinta. Otros ejemplos de ayudas estatales, continúa señalando Song, se pueden encontrar en el Child Benefit, creado en 1976, al que, un año después, le siguió el conocido como One-Parent Benefit. La introducción de éstas y otras medidas legales similares evidencia que todas las familias monoparentales comenzaban a ser ya objeto de atención por parte de las administraciones públicas e instituciones sociales, a diferencia de lo que sucedía en décadas anteriores, cuando tan sólo lo eran las familias monoparentales encabezadas por una mujer viuda.

Se aprecia, por tanto, un cierto paralelismo entre el nacimiento del concepto anglosajón que se utiliza en la actualidad para designar a las estructuras familiares compuestas por un único progenitor a cargo de su descendencia y el cambio en el discurso existente en relación con ellas. De hecho, Julio Iglesias de Ussel (1988: 25 y 26) plantea que la reconceptualización de esta realidad familiar se produjo «como consecuencia de la transformación de un fenómeno antiguo en problema social». Este investigador explica que fueron diversos los factores que transformaron la situación de las familias incompletas en un problema social, aunque, de entre ellos, los decisivos en la construcción de las familias monoparentales fueron cinco. En primer lugar, la expansión que sufrió 
la familia nuclear a partir de la Revolución Industrial. Esto es así porque, según indica Iglesias de Ussel, cuando la vertebración de la familia pasó a basarse en la familia nuclear fue cuando su configuración incompleta se convirtió en un problema social, ya que, en estas formas familiares, disponer de uno o dos progenitores podía repercutir directamente en aspectos como la situación económica, las formas de vida, las posibilidades de trabajo y ocio del adulto responsable de los hijos y el propio proceso de socialización de éstos últimos. En segundo lugar, la dilación en la emancipación de los hijos. Así, aspectos como la escolarización global de la población, su prolongación y el retraso legal en la edad de incorporación al mercado laboral son beneficios colectivos muy positivos, afirma Iglesias de Ussel, pero en ciertos supuestos, como en el de las familias monoparentales, pueden aumentar la duración de la dependencia familiar. Los problemas se producen, por tanto, y según plantea este investigador, «en el momento que la sociedad articula un período de formación prolongado y lo estructura contando con el soporte familiar al sistema escolar", con lo que, «si la familia carece de la composición estandarizada, la situación deviene conflictiva por principio». En tercer lugar, el profundo rechazo que empezó a surgir en el seno de la sociedad hacia cualquier tipo de discriminación, lo que ayudó a que las familias monoparentales se convirtieran en objeto de estudio, surgiera el concepto que se utiliza actualmente para designarlas y se emprendieran medidas de política social en todos los estados democráticos. En cuarto lugar, la creciente multiplicación de las familias monoparentales, producida, en parte, por aspectos como el incremento en las prácticas sexuales previas al matrimonio, el aumento en el número de divorcios y separaciones conyugales, la reivindicación del derecho a la maternidad libremente elegida al margen de la vinculación matrimonial, la incorporación de la mujer al mercado laboral, etc. En quinto, y último, lugar, Julio Iglesias de Ussel destaca que no se puede ocultar el hecho de que estas situaciones familiares se convirtieron en un problema social cuando la situación empezó a afectar a otras clases sociales diferentes a las implicadas anteriormente. Cuando la situación incidía primordialmente en las clases bajas de la sociedad, la respuesta legal era la discriminación, mientras que la reacción colectiva era la censura. En cambio, cuando comenzaron a generalizarse a otras clases sociales, las reacciones se matizaron y empezaron a surgir voces demandando reformas legales que afrontaran, civilizada y progresivamente, esa realidad familiar considerada por algunos, incluso, como novedosa. Este investigador concluye que el cambio en los protagonistas de las familias monoparentales o, mejor dicho, la ampliación de la base social de procedencia, fue el factor determinante a la hora de considerarlas como un problema social.

Después de aparecer en zonas como Estados Unidos e Inglaterra, el resto de países desarrollados fueron, poco a poco, experimentando cambios culturales y demográficos orientados en la misma dirección, lo que hizo que también en ellos surgiera un nuevo discurso en torno a las familias monoparentales, así como la necesidad de introducir otras categorías conceptuales diferentes a las empleadas hasta el momento. Por la cercanía, no sólo física, sino también cul- 
tural y académica, que presenta con respecto a España, es interesante analizar, brevemente, el origen del concepto francés.

Expertos en la materia de este país, como Nadine Lefaucheur y Claude Martin (1997: 223), explican que fue durante la segunda mitad de los años setenta cuando tuvo lugar en Francia la aparición del término familles monoparentales, traducido del anglosajón lone-parent families. Este nuevo concepto, introducido por las sociólogas feministas Andrée Michel, Anne-Marie Estève, Colette Verlhac y Nadine Lefaucheur, nacía con la clara intención de permitir a los hogares a cargo de una mujer acceder a la categoría de verdaderas familias, pues, según defendían sus promotoras, las mujeres eran perfectamente capaces de criar en solitario a sus hijos. Asimismo, argumentaban que todas las familias monoparentales, independientemente del sexo y del estado civil del progenitor a su cargo, debían ser consideradas tan reales como el resto, a la par que representaban un estilo de vida igualmente respetable. Se observa, por tanto, que, además de ser un logro conceptual de la sociología feminista, el nacimiento de este nuevo concepto tenía un carácter claramente reivindicativo, ya que, como señala la propia Lefaucheur (1988: 156), pretendía enfatizar, por una parte, lo que representaba el concepto, es decir, el grupo monoparental en sí mismo y no el hecho de que la mujer fuera la responsable de ese grupo, y, por otra, el marco de referencia, esto es, la estructura familiar y no la condición femenina que caracterizaba a estos grupos.

En términos generales, el concepto fue bien recibido por diversos sectores como los medios de comunicación, los trabajadores sociales y gran parte de los grupos políticos, con lo que el carácter negativo que normalmente se atribuía a este tipo de hogares empezó a desaparecer ${ }^{6}$. A finales de los años setenta, el uso de este nuevo concepto se generalizó dentro de diversas áreas de las ciencias sociales, como la sociología y la demografía, y se hizo presente también en numerosos medios de comunicación, quienes lo utilizaban ya no sólo para describir un modelo de familia tan normal como el resto, sino también para hacer referencia a todos aquellos hogares en los que existía un único progenitor a cargo de sus hijos, independientemente del estado civil que presentase ese progenitor. Organismos como el Caisse Nationale des Allocations Familiales, el École des Parents et des Educateurs y el National Institute of Demographic Studies (INED) empezaron a publicar, por su parte, diversos documentos y artículos en los que hacían referencia explícita a las familles monoparentales, con lo que desechaban el uso de otros conceptos anteriores. En 1981, y como aspecto más destacado, el National Institute of Statistics and Economic Studies (INSEE) decidió incluir la categoría familles monoparentales dentro de la tipología que sobre hogares había elaborado, de manera que esta realidad familiar pasó a ser considerada una de las tres grandes formas de convivencia dominantes en el panorama social francés (Lefaucheur, 1986: 77).

6. Lefaucheur y Martin añaden que, en algunos casos, estos hogares llegaron a ser considerados, incluso, más modernos que el resto, al ser más innovadores en cuando a sus roles sexuales (Lefaucheur y Martin, 1997: 223; Lefaucheur, 1988: 156). 
Pese al éxito del término y a los logros alcanzados por la sociología feminista, la referencia explícita o implícita a dos tipos de problemas sociales, relacionados ambos con la socialización de los hijos en los grupos monoparentales, fue lo que, según lamenta Lefaucheur (1988: 157), continuó sosteniendo en la mayoría de los casos el uso social de la categoría famille monoparental. Estos dos tipos de problemas sociales, explica esta investigadora, se centraban, por una parte, en las dificultades socioeconómicas que estas formas familiares presentaban, ligadas, en la mayoría de los casos, a la degradación de la situación material que suponía la transformación de un grupo biparental en un grupo monoparental, y, por otra, en las complicaciones psicosociales que resultaban de la presencia de un único progenitor en el grupo familiar, con las consecuencias negativas que ello podía tener para la socialización de los hijos.

Lo cierto es que, aunque se está hablando de la situación concreta que presentaban las familias monoparentales francesas, la referencia continua a estos dos tipos de problemas sociales se fue haciendo cada vez más presente e intensa en prácticamente todos los países desarrollados. En efecto, muchas familias monoparentales femeninas llegaron a tener una situación económica complicada que las posicionó, en varios casos, por debajo de los umbrales mínimos de pobreza y las hizo depender claramente de subsidios u otras ayudas económicas. Igualmente, diversas investigaciones pusieron de manifiesto que los niños se desarrollaban más plenamente cuando los dos progenitores se encontraban presentes y ejercían un papel activo en pro de su crecimiento, lo que no siempre sucedía, ya que, bien de forma voluntaria, bien de forma involuntaria, uno de los progenitores, en la mayoría de los casos el padre, se encontraba ausente.

Como consecuencia de los problemas sociales que presentaban y del incremento tan acentuado que estaban experimentando en la mayoría de los países desarrollados, las familias monoparentales femeninas llegaron a constituirse, en el curso de los años noventa, como una de las máximas prioridades dentro de la agenda política de diversos estados democráticos, quienes se vieron en la necesidad de ir adoptando políticas dirigidas hacia el apoyo social y económico de estas formas de hogar. No obstante, la literatura feminista de los años noventa, bastante crítica con la atención que, desde los poderes públicos, se concedía a las familias monoparentales femeninas, plantea que no todas las políticas sociales diseñadas se orientaron en la misma dirección, puesto que éstas se encontraban estrechamente vinculadas a la percepción social e histórica que los estados democráticos tenían con respecto a las mujeres y sus funciones dentro del conjunto de la sociedad.

La socióloga feminista Jane Lewis (1992), que es probablemente una de las que más ha reflexionado al respecto, señala que en varios países, como Irlanda, Noruega, Inglaterra y Holanda, la tradicional división de roles, según la cual el hombre era el encargado del mantenimiento económico de la unidad familiar, mientras que la madre y esposa se centraba en el cuidado de los hijos (male-breadwinner family model), ejercía todavía un peso importante sobre el conjunto de la sociedad. En consecuencia, el estado, acorde con estas creencias, 
percibía que las mujeres eran ante todo madres, por lo que la política social diseñada con respecto a las familias monoparentales femeninas debía respetar y promover ese papel tan determinante que tenían las mujeres en el cuidado y la crianza de sus hijos. Jane Lewis y Barbara Hobson (1997: 15 y 16) explican que, entre las medidas adoptadas de acuerdo con esta actitud, se encuentran, por ejemplo, ciertas ayudas económicas que, a modo de salario, se concedían a las mujeres monoparentales que, como requisito indispensable, no se encontraran dentro del mercado laboral. Estas ayudas se extendían durante los años que duraba la crianza y el cuidado de los hijos, lo que permitía a las mujeres dedicarse plenamente a su descendencia.

En el lado opuesto, se encontraban las políticas sociales de otros países como Suecia, donde la atención se centraba en el papel tan importante que las mujeres asumían como miembros activos del mercado laboral, es decir, como trabajadoras. En estos países, la tradicional división de roles había ido perdiendo peso, en pro de un nuevo modelo de convivencia fundamentado en el reparto igualitario de las tareas entre ambos sexos (dual breadwinner model, como lo denomina Lewis). En base a este modelo, y a las creencias existentes con respecto a las mujeres, las políticas sociales referidas a las familias monoparentales femeninas buscaban apoyar a las madres trabajadoras, a través de medidas políticas y legales, como la creación de guarderías y servicios que permitieran conciliar la vida familiar con la vida laboral y la adopción de mejoras dentro de la política diseñada en torno a la maternidad (permisos de maternidad más amplios, flexibilidad horaria, etc.).

Se observa, por tanto, y según concluyen Lewis y Hobson, que cada estado prestaba un tratamiento específico a la monoparentalidad en función de la percepción que tenía con respecto a las mujeres. En concreto, los problemas y las discrepancias, en términos de política social, venían generados por el choque de creencias que se producía en relación con los roles que las mujeres habían de asumir por su condición femenina. Unos, los estados más conservadores y afines a la tradicional división de roles existente durante siglos, defendían el papel de la mujer como madre y cuidadora, lo que daba lugar a un modelo que las feministas han denominado the Caregiver Social Wage Model. Otros, los más progresistas y liberales, enfatizaban el papel que estas mujeres asumían como trabajadoras y, en consecuencia, perceptoras de sus propios ingresos económicos, en lo que se ha venido a denominar the Parent Worker Model. Como aspecto a destacar, Lewis y Hobson apuntan, después de analizar el caso concreto de diversos estados europeos, que algunos de ellos, sobre todo los más conservadores, muestran, desde hace unos años, claros indicios de estar caminando hacia un modelo de política social basado en la madre trabajadora.

En torno, asimismo, a los problemas y a las dificultades que presentan las estructuras monoparentales femeninas en gran parte de los países desarrollados, resulta interesante concluir este apartado señalando que, en determinadas zonas como Estados Unidos, ya están empezando a surgir ciertos críticos que, entroncando con las posiciones más conservadoras de los años cincuenta y sesenta, defienden firmemente la idea de que los cambios que se han venido 
produciendo durante las últimas décadas en relación con la familia y las pautas demográficas a ella asociadas, lejos de beneficiar a la familia como institución social, están provocando su debilitamiento. El experto David Popenoe (1993, 1996) es uno de los académicos que, defensores de esta creencia, denuncia abiertamente el declive que, a nivel demográfico, institucional y cultural, ha ido experimentando la familia americana desde finales de los años sesenta, momento en el que se comenzó a generalizar, según él mismo la ha denominado, esa cultura del divorcio y del no matrimonio de la que se hablaba al inicio de este epígrafe. Este declive, señala Popenoe (1993: 539), debe ser entendido como un hecho único y alarmante, pues está afectando de lleno a lo que puede considerarse como el último vestigio de la unidad familiar tradicional, esto es, la familia nuclear biparental. Igualmente, está teniendo unas consecuencias desastrosas para niños y jóvenes, que, además de constituirse ya como uno de los grupos sociales más pobres de Estados Unidos, están creciendo, en la mayoría de los casos, en una familia monoparental femenina, alejados, por tanto, de sus progenitores varones. Este último aspecto, destaca Popenoe, es muy preocupante, sobre todo teniendo en cuenta que un número importante de analistas ha argumentado que el incremento en el número de hogares monoparentales femeninos, así como el desvanecimiento de la figura paterna que se produce tras una ruptura sentimental o un nacimiento fuera del matrimonio, parecen ser las principales causas de parte de los problemas sociales que azotan a este país.

\section{La monoparentalidad en la España cambiante de finales del siglo XX. Origen del concepto español}

El caso concreto de España fue especial, ya que el origen del concepto familia monoparental, traducido del francés famille monoparental, no se produjo hasta prácticamente la década de 1980 . Se observa, por tanto, que su nacimiento aconteció con cierto retraso con respecto al momento en el que se introdujo en otros países. El motivo de ese retraso se encuentra en la propia situación social, familiar y política que presentaba España durante los años sesenta y setenta, la cual imposibilitaba el reconocimiento y la aceptación social de las situaciones monoparentales y, por consiguiente, su reconceptualización.

Diversos aspectos como los valores tradicionales, la propia realidad social y familiar, la influencia de la Iglesia y, por supuesto, la ideología y el sistema político vigentes, fueron dotando a las situaciones monoparentales españolas de un carácter negativo, inmoral y sancionable, que provocó, en determinados casos, la adopción de serias represalias sociales y legales contra ellas. Esta opresión social, así como la percepción negativa y el discurso moralista que existían, se mantuvieron, prácticamente, durante toda la época franquista, aunque con menor peso durante los últimos años. Nuevamente, y al igual que en el resto de países desarrollados, se observaba la existencia de una clara jerarquía entre las distintas situaciones monoparentales en función de la causa que había generado su condición. Así, las situaciones encabezadas por una mujer 
viuda, al ser consideradas involuntarias, despertaban un menor rechazo a nivel social y moral, frente a las madres solteras, que eran las que mayor desdén y deshonra provocaban, y que, incluso, podían llegar a ser recluidas durante años en los centros del Patronato de Protección a la Mujer, dependientes del Ministerio de Justicia de la época y creados, precisamente, para velar por las mujeres caidas.

El advenimiento de la democracia en el año 1975 supuso un cambio radical para todas aquellas situaciones familiares cuya estructura no se ajustaba a la del modelo dominante. Según explica Julio Iglesias de Ussel (1994: 418), la transición democrática significó, por una parte, «la supresión del modelo tradicional de familia", que presentaba una larga trayectoria histórica en nuestra sociedad y que, además, era el único que durante la época franquista contaba con un respaldo legal, y, por otra, su sustitución "por el pluralismo de las distintas alternativas familiares, muchas de ellas ya con tratamiento legal específico, pero todas sin riesgo de sanciones o discriminaciones».

Si el análisis se centra concretamente en las situaciones monoparentales, se aprecia que, con la llegada de la democracia, estas formas familiares experimentaron una profunda transformación a consecuencia de los diversos cambios jurídicos, sociales y demográficos, entre otros, que empezaron a producirse en la sociedad (Iglesias de Ussel, 1998).

En relación con los primeros, los cambios jurídicos, el sistema español se modificó completamente, de manera que se eliminaron las trabas y las sanciones legales que existían durante la época franquista. Entre las diversas medidas que se fueron introduciendo, destaca, por la relevancia que tuvo en la constitución de situaciones monoparentales, la Ley de divorcio de 7 de julio de 1981. Su entrada en vigor supuso la aparición, ese mismo año, de un elevado número de divorcios que, en la mayoría de los casos, eran separaciones de hecho que, con la implantación de la nueva ley, optaron por regular jurídicamente su situación. Posteriormente, el número de divorcios disminuyó hasta el año 1986, momento en el que comenzaron a aumentar, lo que provocó un incremento sostenido en el número de situaciones monoparentales. De hecho, esta última fecha puede ser entendida como clave para la monoparentalidad española, pues fue el momento en el que, como consecuencia del incremento continuo, pero moderado, en las tasas de divorcio, las situaciones monoparentales generadas por el fallecimiento de uno de los cónyuges, comúnmente el marido, dejaron de ser mayoritarias dentro del conjunto de la monoparentalidad, y cedieron así el lugar que tradicionalmente habían ocupado a las situaciones monoparentales creadas a partir de un divorcio o una ruptura matrimonial. Fue de esta manera como se inició, no sólo el incremento en la frecuencia con la que se daba una situación monoparental en la sociedad española, sino también un importante proceso de redistribución interna en esta categoría familiar.

Además de los cambios en la esfera jurídica, la transición política trajo consigo modificaciones a nivel social e ideológico. Las madres solteras, por ejemplo, empezaron a liberarse del estigma y la censura que las habían perseguido durante toda la época franquista. Este hecho, unido a la aceptación social 
progresiva de fenómenos como la cohabitación y el divorcio, y a una paulatina liberalización en términos sexuales, fueron, igualmente, promoviendo, aunque más bien a largo plazo, la constitución de diversas estructuras monoparentales, encabezadas, sobre todo, por las generaciones más jóvenes de la época.

Junto a estos aspectos, se empezaron a suceder toda una serie de cambios demográficos que, además de contribuir a aumentar el número de estructuras monoparentales, hicieron que España se acercara a la realidad demográfica imperante en el resto de países desarrollados. A partir de 1975, por ejemplo, se inició un descenso en las tasas de nupcialidad y un aumento en la cohabitación, que era una tendencia que llevaba ya algunos años produciéndose en otros países. La tasa de natalidad, por su parte, comenzó a experimentar un descenso continuo en sus niveles en 1964, con lo que se convirtió en uno de los primeros indicadores demográficos que sufría variaciones orientadas en la misma dirección que las de otros países. En conexión directa con el descenso de estos dos fenómenos demográficos, nupcialidad y natalidad, a principios de los ochenta, se empezó a producir un importante retraso en el calendario nupcial, por lo que aumentó la edad media a la que se contraía matrimonio.

El conjunto de cambios jurídicos, sociales y demográficos registrados en España a raíz de la transición democrática hicieron que las estructuras monoparentales dejaran de ser entendidas como marginales o desviadas y se fueran desprendiendo del discurso que, durante bastante tiempo, las había problematizado en términos moralistas. Igualmente, y como ya se ha señalado, este conjunto de cambios provocó un incremento progresivo en el número de estructuras monoparentales, lo que permitió, y asimismo promovió, su reconocimiento y aceptación social. Esto favoreció la aparición del concepto que actualmente se utiliza para referirse a ellas. Por tanto, el nacimiento del término español familia monoparental puede ubicarse a partir de la transición democrática de 1975, más concretamente, a mediados de los años ochenta.

En el momento en el que las situaciones monoparentales comenzaron a ser entendidas como un problema social en nuestro país, empezaron a generarse una serie de análisis e investigaciones sociales sobre las características y las peculiaridades que éstas presentaban. Pese a ello, determinados sectores percibían todavía una cierta falta de atención con respecto al estudio de estas formas familiares. Por ese motivo, Julio Iglesias de Ussel, junto a un grupo destacado de especialistas españoles y franceses, decidieron organizar, con la colaboración del Instituto de la Mujer, el Centre National de la Recherche Scientifique (CNRS), de Francia, y la CAYCIT, del Ministerio de Educación e Investigación, el primer seminario sobre familias monoparentales en nuestro país. Éste acabó celebrándose finalmente en Madrid en diciembre de 1987 y acogió a científicos sociales de ambos países, como Inés Alberdi, M. ${ }^{a}$ Ángeles Durán, Nadine Lefaucheur y Claude Martin. La relevancia que tuvo fue tan grande que algunos investigadores han terminado considerándolo como el momento clave en el que tuvo lugar la presentación oficial del término familia monoparental en la sociología de la familia española. 
Desde el inicio de su expansión a finales de los años ochenta, el interés que ha suscitado este objeto de estudio ha sido tal, que Julio Iglesias de Ussel (1998: 237) ha llegado a plantear que "pocas expresiones han adquirido tan fulminante éxito en las ciencias sociales como la de "familias monoparentales"». De hecho, y según continúa señalando este mismo investigador, «en el campo de la sociología de la familia no existe ninguna otra que haya logrado difusión internacional en un período de tiempo tan corto». Los aspectos que han propiciado este interés por las situaciones monoparentales, así como la difusión científica y social del concepto que se utiliza en la actualidad para designarlas, están profundamente vinculados a los problemas sociales que estas formas familiares acarrean y a la preocupación que, en consecuencia, existe en torno a su constitución. El debate social en España a propósito de la monoparentalidad se ha centrado, al igual que en otros países, en el análisis de las dificultades económicas que estas formas familiares presentan, así como en los problemas psicosociales que podría llegar a generar en el niño la ausencia de uno de los progenitores.

Aunque en nuestro país no existe una ley nacional que reconozca los derechos y deberes de las estructuras monoparentales, sí que existen ciertas medidas puntuales, tanto ministeriales como autonómicas y locales, dictadas en su favor. Entre ellas, se encuentran las dirigidas a regular aspectos como la concesión de ciertas ayudas y subvenciones públicas, el nacimiento de programas de apoyo y asistencia social o la concesión de algún tipo de preferencia. No obstante, asociaciones y movimientos sociales consideran que, ante los duros problemas que oprimen a la realidad monoparental de nuestro país, estas medidas son insuficientes para paliar las dificultades, sobre todo a nivel económico, que estas formas familiares presentan. Por ello, uno de sus principales objetivos se centra en presionar al sistema político, buscando promover medidas más completas y eficientes que las anteriores y que beneficien a todas las familias monoparentales. Un ejemplo de la labor que desarrollan se encuentra en la acción que les ha venido ocupando durante los últimos años, consistente en lograr que todas las familias monoparentales que tengan más de un hijo sean consideradas familias numerosas y puedan gozar, por ende, de los mismos derechos que tienen éstas. Igualmente, denunciando que las situaciones monoparentales españolas se encuentran en una especie de limbo jurídico, buscan conseguir la elaboración de algún tipo de ley orientada hacia su protección jurídica integral.

Otro de los aspectos que critican no sólo las asociaciones españolas, sino también las propias familias monoparentales, es que, además de no existir un consenso jurídico sobre lo que cada comunidad autónoma entiende por familia monoparental, este concepto engloba una amplia pluralidad de realidades familiares muy diferentes entre sí. Por tanto, y desde un punto de vista práctico, consideran que este concepto resulta inoperativo, pues las circunstancias concretas que presenta cada una de estas familias, en base a aspectos como la causa que ha generado la monoparentalidad, la edad y el sexo del progenitor a cargo del grupo, la situación laboral de éste, etc., son muy particulares, lo que hace que no todas las situaciones monoparentales sean iguales. 


\section{Reflexiones finales}

Si bien desde su nacimiento, en la década de 1980, todos los grupos familiares compuestos por un único progenitor a cargo de su descendencia han quedado englobados bajo una misma categoría, la monoparentalidad, ya están empezando a surgir voces en nuestra sociedad que, como se ha señalado anteriormente, no están de acuerdo con la homogeneidad que este concepto insinúa. En consecuencia, están demandando la necesidad de diferenciar, terminológicamente hablando, entre ambos tipos de monoparentalidad, la masculina y la femenina, pues, según plantean, los problemas, las necesidades y las características que presentan estos grupos familiares difieren en función del sexo del progenitor que se encuentra al frente de ellos.

Es así como, desde principios del siglo XXI, se está asistiendo al nacimiento del término familias monomarentales, que, de la mano de diversos grupos de presión y respaldado por determinados académicos y partidos políticos, ha hecho su aparición en nuestra sociedad con el objetivo de designar a todas aquellas estructuras familiares en las que es la madre la que asume en solitario el cuidado de sus hijos dependientes. Este nuevo concepto desplaza, por tanto, al término monoparental, que, según exponen, no resulta neutral desde un punto de vista del género y quedaría reservado para nombrar tan sólo a aquellas estructuras familiares en las que es el padre el que asume el cuidado de su descendencia.

Ante el nacimiento del término familia monomarental, ya son varios los sectores sociales que, además de aplaudir la iniciativa, lo han incorporado en sus discursos respectivos, puesto que lo consideran un término innovador y positivo, que dota de una mayor visibilidad tanto a las estructuras monomarentales como a las monoparentales. Entre los ejemplos más recientes de su uso, se pueden encontrar diversas aportaciones científicas, como las de las investigadoras Elisabet Almeda (2008), Cristina Carrasco (1997), María Eugenia González (2003), Beatriz Morgado, Irene Jiménez y María del Mar González (2003, 2004), etc., quienes, en términos generales, afirman que, en la mayoría de los casos, son las mujeres las que se encuentran al frente de este tipo de hogares, por lo que resulta más acertado denominarlos monomarentales que monoparentales. Igualmente, durante los últimos años, se han celebrado en nuestro país diversas jornadas sobre la situación específica que presentan las familias monomarentales. Un ejemplo lo constituyen las que, a cargo de la Federación de Asociaciones de Madres Solteras, vienen desarrollándose desde principios del siglo XXI en distintos puntos de la geografía española bajo lemas como «Madres solteras invisibles» (León, 2006), «Creamos redes» (Madrid, 2008), «Familias monomarentales: Conciliar la vida laboral, familiar y personal» (Valencia, 2009), «Políticas familiares y monomarentalidad» (Madrid, 2010), etc. El propio Boletín Oficial del Estado recoge, en el artículo 8 de su Resolución de 29 de abril de 20087, una definición sobre este

7. Resolución de 29 de abril de 2008, del Instituto de la Mujer, por la que se convoca la edición de las subvenciones al empleo "Emprender en Femenino» del año 2008, para fomentar la inserción laboral de las mujeres por cuenta propia (Boletín Oficial del Estado, 121, de 19.5.2008). 
término, planteando que «se considerará familia monomarental la formada por una mujer que tenga a su cuidado a menores de 21 años o mayores con discapacidad que no obtengan ingresos de cualquier naturaleza superiores al $75 \%$ del salario mínimo interprofesional vigente en el momento de publicación de esta Resolución».

Por el contrario, y como sucede con todo nuevo concepto que se precie, no han faltado quienes también lo han criticado, afirmando que se trata de una expresión artificial, forzada, oportunista, innecesaria y lingüísticamente incorrecta, pues el término parental engloba a ambos progenitores, tanto al padre como a la madre, por lo que calificar a una estructura de monoparental implica, ya de por sí, que ésta se encuentra compuesta por uno sólo de esos progenitores y sus hijos.

Como se observa, el debate está abierto, y sólo queda hacerse una pregunta: ¿Estamos asistiendo al inicio de un nuevo proceso de reconceptualización similar al que se produjo durante la segunda mitad del siglo XX, cuando las estructuras compuestas por un único progenitor dejaron de ser consideradas rotas e incompletas, entre otros calificativos, para pasar a ser entendidas como monoparentales? Sólo el tiempo lo dirá. Por el momento, parece que el cambio conceptual que se busca introducir pretende reivindicar tan sólo la naturaleza femenina de la monoparentalidad, por lo que no resulta tan radical como lo fue el registrado a finales del siglo XX. Además, se trata de una iniciativa más bien puntual y que goza de cierto carácter nacional, pues en otros países, como Estados Unidos, sí existe una terminología concreta, más o menos aceptada por todos, que permite distinguir entre estructuras monoparentales masculinas y femeninas ${ }^{8}$. Tan sólo en los países francófonos es posible encontrar ciertas muestras de interés por el uso del término famille monomarental. Nos encontramos, por tanto, ante un nuevo concepto que está dando sus primeros pasos en nuestra sociedad y cuyo futuro resulta aún incierto.

\section{Referencias bibliográficas}

AlmEDA, Elisabet (2008). «Famílies monomarentals: Visibilitzant les realitats». En: BODELÓN, Encarna y GiméNEZ, Pilar (coord.). Construint els drets de les dones: Dels conceptes a les politiques locals. Barcelona: Diputació de Barcelona, 205-218.

BARRÓN, Sara (1998). «La construcción socio(ideo)lógica de la monoparentalidad: Ideología familiar biparental, silenciamiento y victimismo». Inguruak: Revista Vasca de Sociología y Ciencia Política, 21, 203-225.

Biller, Henry B. (1968). «A Note on Father Absence and Masculine Development in Lower-Class Negro and White Boys». Child Development, 39 (3), 1003-1006.

- (1969). «Father Absence, Maternal Encouragement, and Sex Role Development in Kindergarten-Age Boys». Child Development, 40 (2), 539-546.

8. En estos países, se emplean los términos single/lone-father families y singlellone-mother families para distinguir entre las familias monoparentales masculinas y femeninas, respectivamente. El concepto single/lone-parent families, por su parte, se utiliza para designar al conjunto de la monoparentalidad. 
CARrasco, Cristina (1997). «Mujeres, trabajos y políticas sociales en España». Duoda: Revista d'Estudis Feministes, 13, 85-104.

Cliquet, Robert (1991). The Second Demographic Transition: Fact or Fiction? Estrasburgo: Council of Europe. Population Studies; 23.

DEVEN, Freddy (1986). "A review of trends in the research on One-Parent Families». En: Deven, Freddy y Cliquet, Robert (eds.). One-Parent Families in Europe. La Haya / Bruselas: NIDI/CBGS Publications, 15, 13-27.

DurÁn, M.a Ángeles (1988). "Hogares y familias: dos conceptos en busca de definición». En: IGLESIAS DE UsSEL, Julio (ed.). Las familias monoparentales. Madrid: Instituto de la Mujer. Ministerio de Asuntos Sociales, 11-22. Debate; 5.

FERnÁndEZ, Juan Antonio y ToBío, Constanza (1998). «Las familias monoparentales en España». Revista Española de Investigaciones Sociológicas, 83, 51-85.

Finch, Janet y Summerfield, Penny (1999). "Social Reconstruction and the Emergence of Companionate Marriage, 1945-1959». En Allan, Graham (ed.). The Sociology of the Family: a reader. Oxford: Blackwell Publishers, 12-34.

GonZÁleZ, María Eugenia (2003). «El análisis sociológico de la familia actual». En: POYATOS, Ana (coord.). Mediación familiar y social en diferentes contextos. Valencia: Nau Llibres, 15-46.

GonZÁlez, María del Mar; Jiménez, Irene y Morgado, Beatriz (2003). «Familias monomarentales: problemas, necesidades y recursos». Portularia: Revista de Trabajo Social, 3, 137-160.

IGLESIAS DE USSEL, Julio (1988). «La situación de la familia en España y los nuevos modelos familiares». En: IGLESIAS DE UsSEL, Julio (ed.). Las familias monoparentales. Madrid: Instituto de la Mujer. Ministerio de Asuntos Sociales, 23-40. Debate; 5 .

- (1994). «La familia». En: V informe sociológico sobre la situación social en España, vol. 1. Madrid: Fundación FOESSA, 415-547.

- (1998). La familia y el cambio político en España. Madrid: Tecnos.

INGLEHART, Ronald (1998). Modernización y posmodernización: El cambio cultural, económico y político en 43 sociedades. Madrid: CIS. Monografías; 161.

JiméneZ, Irene; Morgado, Beatriz y GonZÁlez, María del Mar (2004). «Familias monomarentales y exclusión social». Portularia: Revista de Trabajo Social, 4, 249260.

LAMB, Michael E. (1986). "The Changing Roles of Fathers». En: LAMB, Michael E. (ed.). The Father's Role: applied perspectives. Nueva York: John Wiley \& Sons, 3-27.

Lefaucheur, Nadine (1986). "How the One-Parent Families appeared in France». En: Deven, Freddy y Cliquet, Robert (eds.). One-Parent Families in Europe. La Haya / Bruselas: NIDI/CBGS Publications, 15, 73-81.

- (1988). «Existen las familias monoparentales?». En: IGLESIAS DE Ussel, Julio (ed.). Las familias monoparentales. Madrid: Instituto de la Mujer. Ministerio de Asuntos Sociales, 153-161. Debate; 5.

Lefaucheur, Nadine y MarTin, Claude (1997). «Single Mothers in France: Supported Mothers and Workers». En: DunCAN, Simon y EDWARDS, Rosalind (eds.). Single Mothers in an International Context, Mothers or Workers? Londres: UCL Press, 217-239.

Lesthaeghe, Ron (1995). «The Second Demographic Transition in Western Countries: An Interpretation». En: MASON, Karen Oppenheim y JENSEN, An-Magritt (eds.). Gender and Family Change in Industrialized Countries. Oxford: Clarendon Press, 15-62. 
LEWIS, Jane (1992). "Gender and the Development of Welfare Regimes». Journal of European Social Policy, 2 (3), 159-173.

LEWIS, Jane y HobSON, Barbara (1997). «Introduction». En: LEWIS, Jane (ed.). Lone Mothers in European Welfare Regimes. Londres: Jessica Kingsley Publishers, 1-20.

LEWIS, Jane y Kiernan, Kathleen (1996). "The Boundaries between Marriage, Nonmarriage, and Parenthood: Changes in Behavior and Policy in Postwar Britain». Journal of Family History, 21 (3), 372-387.

Lima, Lowell y HARRIS, Robert (1988). "The Child Support Enforcement Program in the United States». En: KaHn, Alfred y Kamerman, Sheila (eds.). Child Support: from debt collection to social policy. Newbury Park: Sage Publications, 20-44.

O'Connell, Helen (1994). Women and the Family. Londres: Zed Books Ltd.

Popenoe, David (1993). "American Family Decline, 1960-1990: A Review and Appraisal». Journal of Marriage and Family, 55 (3), 527-542.

- (1996). Life without father. Nueva York: The Free Press.

REES, Philip (1996). The Second Demographic Transition: What Does it Mean for the Future of Europe's Population? Leeds: School of Geography. University of Leeds. Working Paper, 96/19.

REHER, David Sven (1996). La familia en España, pasado y presente. Madrid: Alianza.

Russell, Ivan L. (1957). «Behavior Problems of Children from Broken and Intact Homes». Journal of Educational Sociology, 31 (2), 124-129.

Song, Miri (1996). "Changing Conceptualizations of Lone Parenthood in Britain: Lone Parents or Single Mums?». European Journal of Women's Studies, 3, 377-397.

Treviño, Rocío (2006). Estructura y dinámica de la monoparentalidad en España. Barcelona: Universitat Autònoma de Barcelona. Departament de sociologia. Tesis Doctoral.

VAN DE KAA, Dirk (1987). Europe's Second Demographic Transition. Washington: Population Reference Bureau, 42 (1). 